\title{
Selective separation of tetramethylammonium hydroxide from mixture of cationic surfactants using nano-composite Ce-silico phosphate
}

\author{
Rizwana Mobin \\ Department of Applied Chemistry, Faculty of Engineering and Technology, Aligarh Muslim \\ University, Aligarh-202002 \\ Email: rizwanambn013@gmail.com
}

Thin layer chromatography is the most popular analytical method used for the separation because it is simple, versatile, cost-effective and rapid [1]. Surfactants are an important class of organic compounds that find applications in pharmaceuticals, cosmetics, food and cleaning products due to its emulsifying, cleaning, foaming, thickening and wetting property [2, 3]. Here, comparative study for the selective separation of tetramethylammonium hydroxide by thin layer chromatography on modified silica gel (Ce-Silico phosphate) with $40 \%$ aqueous ethylene glycol green solvent system as stationary and mobile phases respectively has been presented. From the result, it was found that Ce-silico phosphate was better static phase as compared to silica with $40 \%$ aqueous ethylene glycol for the selective separation of tetramethylammonium hydroxide from the mixture of cationic surfactants.

Table 1: Mobility of cationic surfactants in terms of $\mathrm{R}_{\mathrm{F}}$ values

\begin{tabular}{|l|l|l|l|l|l|l|}
\hline \multirow{3}{*}{ Surfactants } & \multicolumn{4}{|l|}{$\mathbf{R}_{\mathrm{F}}$ value } \\
\cline { 2 - 7 } & \multicolumn{2}{l|}{$\mathbf{M}_{\mathbf{1}}$} & \multicolumn{2}{l|}{$\mathbf{M}_{\mathbf{2}}$} & $\mathbf{M}_{3}$ & $\mathbf{M}_{\mathbf{4}}$ \\
\cline { 2 - 7 } & $\mathbf{S}_{1}$ & $\mathbf{S}_{2}$ & $\mathbf{S}_{1}$ & $\mathbf{S}_{2}$ & $\mathbf{S}_{2}$ & $\mathbf{S}_{2}$ \\
\hline HTAB & 0.02 & 0.02 & 0.20 & 0.20 & 0.32 & 0.64 \\
\hline CPC & 0.02 & 0.03 & 0.18 & 0.18 & 0.31 & 0.61 \\
\hline TMAH & 0.03 & 0.02 & 0.23 & 0.76 & 0.69 & 0.72 \\
\hline CTAB & 0.02 & 0.02 & 0.27 & 0.27 & 0.34 & 0.65 \\
\hline
\end{tabular}

Note- HTAB: Hexadecyltrimethylammnium bromide; CPC: Cetylpyridinium chloride; TMAH: Tetramethylammonium hydroxide; CTAB: Cetyltrimethylammonium bromide $\mathrm{S}_{1}$ : Silica gel G; $\mathrm{S}_{2}$ : Ce-silico phosphate $\mathrm{M}_{1}$ : Double distilled water
$\mathrm{M}_{2}: 40 \%$ aq. ethylene glycol

$\mathrm{M}_{3}: 50 \%$ aq. ethylene glycol

$\mathrm{M}_{4}: 70 \%$ aq. ethylene glycol

Scanning electron microscopy revealed the modified surface structure and chemical composition of silica gel due to the incorporation of cerium phosphate. Transmission electron microscopic study confirms that the prepared Ce-silico phosphate was nano-composite in nature with varying particle size $(14.4,19.0,16.3,20.2$ and 25.3 $\mathrm{nm})$. Thus, silica gel modified with cerium phosphate (Ce-silico phosphate) as static phase showed the enhanced chromatographic performance as compared to silica static phase. Figure 1 shows the densitographic presentation of HTAB and TMAH.

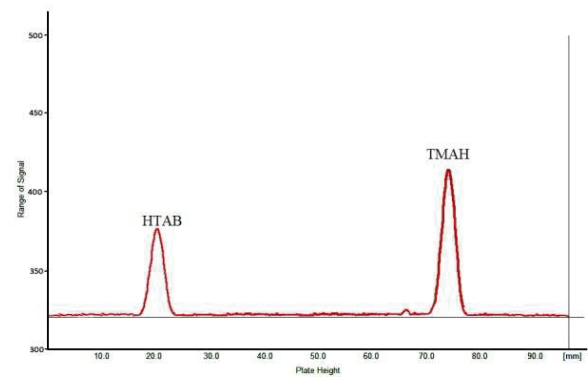

Figure 1: Densitographic presentation of HTAB and TMAH

\section{References}

1. A. Mohammad, S. Hina, Acta Chromatogr., 15 (2005) 238.

2. A. Mohammad, S.A. Bhawani, Chromatographia, 67 (2008) 659.

3. I. Kralova, J. Sjoblom, J. Disper. Sci. Technol., 30 (2009) 1363. 